\title{
CFD study of a sudden-expanding coal combustor using Euler-Euler and Euler-Lagrange models
}

\author{
Yu Zhang *, Xiao-Lin Wei, Da-You Liu \\ Institute of Mechanics, Chinese Academy of Sciences, PR China
}

\section{A R T I C L E I N F O}

\section{Article history:}

Received 8 January 2010

Received in revised form 14 May 2010

Accepted 24 July 2010

Available online 4 August 2010

\section{Keywords:}

Multiphase turbulent flow

Heterogeneous reactions

Particle temperature fluctuation

\begin{abstract}
A B S T R A C T
In this study, the Euler-Euler (E-E) and Euler-Lagrange (E-L) models designed for the same chemical mechanism of heterogeneous reactions were used to predict the performance of a typical suddenexpanding coal combustor. The results showed that the current E-E model underestimated the coal burnout rate because the particle temperature fluctuation on char combustion is not adequately considered. A comparison of the $\mathrm{E}-\mathrm{E}$ and $\mathrm{E}-\mathrm{L}$ simulations showed the underestimation of heterogeneous chemical reaction rates by the E-E model.
\end{abstract}

(c) 2010 Elsevier Ltd. All rights reserved.

\section{Introduction}

Despite high levels of emissions that are dangerous to human and ecosystem health, pulverized coal will continue to be the main fuel for the generation of electricity for some time to come [1]. Computational fluid dynamics (CFD) has become a very powerful tool for the simulation of coal combustion processes and in the design of a coal combustor with low levels of emissions. However, it is very difficult for CFD to make the closure of chemical reaction rate, especially for heterogeneous reactions. An earlier version of a second-order moment (SOM) model has been used to predict NO formation in coal combustion [2]; unfortunately, it gave a significant underestimate because the approximation of $E / R T \ll 1$ made in the series expansion of the exponential function of temperature leads to the elimination of the higher-order terms, which cannot be neglected for $E / R T>5$ in the case of NO formation during coal combustion. A SOM-PDF (probability distribution function) model [3] and a unified SOM (USM) model [4] have been proposed in attempts to improve the SOM models for predicting NO emissions. Those models were first used to simulate pure gas combustion and NO formation and both of them have been verified by experimental data. The results show that the SOM-PDF and USM models are much better for the prediction of NO formation than the EBU-Arrhenius model, the simplified PDF model and the old version of the SOM model. Because of the complexity of the processes, an algebraic unified second-order moment (AUSM) turbulence chemistry model for NO formation under coal combustion

\footnotetext{
* Corresponding author. Tel.: +86 10 82544231; fax: +86 1062561284 .

E-mail address: zhangyu@imech.ac.cn (Y. Zhang).
}

conditions has been proposed. This AUSM model improves the estimation of NO formation but the accuracy is still not sufficient [5]. In this case, the calculation error might stem from inaccurate estimation of the heterogeneous reactions between coal particles and gas, which produce the mass source for NO formation. Considering the heterogeneous reactions, the E-L model has been widely accepted for CFD estimation [6,7]. However, its predictions of coal combustion performance have been claimed to be inadequate for the selection of coal for full-scale utility boilers [8]. Apart from chemical mechanisms, the accuracy of the E-L model depends greatly on the number of particle trajectories; if too few particle trajectories are used in the $\mathrm{E}-\mathrm{L}$ model, the simulation results might not be reliable. A large number of particle trajectories have to be tracked for a utility boiler, which greatly increases the simulation cost.

The E-E model is increasingly accepted for describing twophase flows and chemical reactions $[9,10]$ because of the low cost of calculation. In the E-E model, the particle phase is treated as a fluid phase and the Eulerian method is used to describe both phases. Compared with the E-L model, the E-E model has more potential for use in three-dimensional simulations [11]. There are many reports of the use of the E-E model to predict coal combustion performance. However, the results show that the E-E model always underestimates the burnout rate of coal particles, whether for a swirling coal combustor or for a sudden-expanding coal combustor [5,12]. Underestimation of coal combustion might lead to underestimation of NO emission, especially for hard coal, which has more nitrogen in char. We suggest that the particle phase should be treated as a continuous phase; i.e. it has its own turbulent kinetic energy, stress and so on. If there is fluctuation in the 


\section{Nomenclature}

$\begin{array}{ll}u, u_{p} & \text { gas, particle velocity } \\ \rho, \rho_{p} & \text { gas, particle density } \\ C_{D} & \text { coefficient } \\ \xi & \text { random number } \\ k & \text { gas turbulent kinetic energy } \\ \varphi, \varphi_{p} & \text { general variables of gas, particle } \\ S, S_{p} & \text { source terms of gas, particle }\end{array}$

$\begin{array}{ll}S_{p g}, S_{g p} & \text { exchange source terms between phases } \\ T_{p} & \text { particle temperature } \\ R & \text { heterogeneous chemical reaction rate } \\ d_{r} & \text { average particle diameter } \\ d_{i} & \text { particle diameter of group } i \\ \alpha_{i} & \text { weighted coefficient of group } i\end{array}$

temperature of the gas phase, the particle phase should also have fluctuations of temperature. Obviously, the particle temperature fluctuation must affect the char combustion, just as the gas temperature fluctuation affects the gas combustion. However, for char combustion, most attention has been focused on the details of the reaction kinetics model and the effect of the particle temperature fluctuation has been largely ignored $[13,14]$. In general, the local average particle temperature is still used to predict the heterogeneous chemical reaction rates in the E-E model $[9,10]$.

In order to improve the accuracy of the E-E model, we propose an AUSM turbulence/chemistry reaction model that takes the particle temperature fluctuation into account. However, the model is still crude, in that the particle temperature fluctuation is dependent on the gas temperature fluctuation [12]. Detailed analysis of the particle temperature distribution during combustion is essential for achieving a more reasonable char combustion model.

In this study, we used the E-E and E-L approaches to predict the particle heterogeneous reaction rates and the concentrations of products in a typical sudden-expanding coal combustor. The results showed that the temperatures of particles at a given position within the combustor are not identical; they are distributed within a range. The particles in the combustion zone have two temperature peaks, one of which represents the volatile combustion and the other represents the char combustion. Besides combustion, the temperature values are affected by the transfer of heat between particles and gas. Furthermore, the local average chemical reaction rates of particles estimated by the E-L model are many times greater than that estimated by the E-E model. Consequently, the $\mathrm{E}-\mathrm{E}$ model underestimates the concentration of $\mathrm{CO}_{2}$ and the burnout rate of coal particles.

\section{Numerical methods}

\subsection{The E-L model}

For the E-L simulation, a $k-\varepsilon$ model was used to predict the gas phase turbulence. A conventional discrete random walk model was used for simulating the particle movement in gas turbulence. The heat transfer and chemical reactions between phases are also considered in the E-L simulation [15]. The basic particle momentum equations of the $\mathrm{E}-\mathrm{L}$ model are as follows:

$\frac{d u_{p}}{d t}=F_{D}\left(u-u_{p}\right)+g\left(\rho_{p}-\rho\right)$

$F_{D}=\frac{18 \mu}{\rho_{p} d_{p}^{2}} \frac{C_{D} \operatorname{Re}}{24}$

$u=\bar{u}+u^{\prime}$

$u^{\prime}=\xi\left(\frac{2}{3} k\right)^{1 / 2}$

The commercial software FLUENT has been used in many studies and was used here for the E-L simulation [6,7].

\subsection{The E-E model}

The continuity, momentum, energy and turbulent kinetic energy equations for the gas phase and particle phase are derived and solved in Eulerian coordinates.

The basic equations of 3-D turbulent two-phase reacting flows and coal combustion can be expressed in the following generalized form.

Gas phase equations

$$
\begin{aligned}
& \frac{\partial}{\partial x}(\rho u \varphi)+\frac{\partial}{r \partial r}(r \rho \rho \varphi)+\frac{\partial}{r \partial \theta}(\rho w \varphi) \\
& =\frac{\partial}{\partial x}\left(\Gamma_{\varphi} \frac{\partial \varphi}{\partial x}\right)+\frac{\partial}{r \partial r}\left(r \Gamma_{\varphi} \frac{\partial \varphi}{\partial r}\right)+\frac{\partial}{r^{2} \partial \theta}\left(\Gamma_{\varphi} \frac{\partial \varphi}{\partial \theta}\right)+S_{\varphi} \\
& \quad+S_{\varphi g p}
\end{aligned}
$$

Particle phase equations

$$
\begin{aligned}
\frac{\partial}{\partial x}\left(\rho_{p} u_{p} \varphi_{p}\right)+\frac{\partial}{r \partial r}\left(r \rho_{p} v_{p} \varphi_{p}\right)+\frac{\partial}{r \partial \theta}\left(\rho_{p} w_{p} \varphi_{p}\right) \\
=\frac{\partial}{\partial x}\left(\Gamma_{\varphi p} \frac{\partial \varphi_{p}}{\partial x}\right)+\frac{\partial}{r \partial r}\left(r \Gamma_{\varphi p} \frac{\partial \varphi_{p}}{\partial r}\right)+\frac{\partial}{r^{2} \partial \theta}\left(\Gamma_{\varphi p} \frac{\partial \varphi_{p}}{\partial \theta}\right)+S_{\varphi p} \\
\quad+S_{\varphi p g}
\end{aligned}
$$

where $\varphi$ and $\varphi_{p}$ are the generalized independent variables of gas and particle, and $S_{\varphi}$ and $S_{\varphi p}$ are their source terms induced by the actions within each phase. $S_{\varphi g p}$ and $S_{\varphi p g}$ are the exchanging source terms induced by the interactions between phases. The meanings of variables and other terms are given in Ref. [16]. An in-house CFD code, developed by the authors, was used for the EE simulation.

When heterogeneous chemical reactions take place the mass exchange must happen at the interface of particle and gas, and the resulting new source terms will appear in both $S_{\varphi g p}$ and $S_{\varphi p g}$. For $S_{\varphi g p}$, the general form of the new source term is:

$S_{n}=-\varphi \sum_{p} n_{p} \dot{m}_{p}$

where $n_{p}$ represents the particle number and $\dot{m}_{p}$ is the statistically averaged heterogeneous chemical reaction rate. In this situation, $S_{n}$ is predominant in the source terms, and the accurate prediction of $\dot{m}_{p}$ becomes crucial.

\subsection{Char combustion sub-models}

Assuming that there are three chemical reactions on the surface of char:

$$
\begin{aligned}
& \mathrm{C}+\mathrm{O}_{2} \rightarrow \mathrm{CO}_{2} \\
& 2 \mathrm{C}+\mathrm{O}_{2} \rightarrow 2 \mathrm{CO} \\
& \mathrm{C}+\mathrm{CO}_{2} \rightarrow 2 \mathrm{CO}
\end{aligned}
$$


then:

$$
\begin{aligned}
& \dot{m}_{c, p}^{1}=-\frac{1}{\beta_{c 1}} \pi d_{p}^{2} \rho_{S} Y_{\mathrm{O}_{2}, S} B_{1} \times 0.5 \times\left(\exp \left(\frac{E_{1}}{R\left(\overline{T_{p}}+1 / 2 T_{p}^{\prime}\right)}\right)+\exp \left(\frac{E_{1}}{R\left(\overline{T_{p}}-1 / 2 T_{p}^{\prime}\right)}\right)\right) \\
& \dot{m}_{c, p}^{2}=-\frac{1}{\beta_{c 2}} \pi d_{p}^{2} \rho_{S} Y_{\mathrm{O}_{2}, S} B_{2} \times 0.5 \times\left(\exp \left(\frac{E_{2}}{R\left(\overline{T_{p}}+1 / 2 T_{p}^{\prime}\right)}\right)+\exp \left(\frac{E_{2}}{R\left(\overline{T_{p}}-1 / 2 T_{p}^{\prime}\right)}\right)\right) \\
& \dot{m}_{c, p}^{3}=-\frac{1}{\beta_{c 3}} \pi d_{p}^{2} \rho_{S} Y_{\mathrm{CO}_{2}, S} B_{3} \times 0.5 \times\left(\exp \left(\frac{E_{3}}{R\left(\overline{T_{p}}+1 / 2 T_{p}^{\prime}\right)}\right)+\exp \left(\frac{E_{3}}{R\left(\overline{T_{p}}-1 / 2 T_{p}^{\prime}\right)}\right)\right)
\end{aligned}
$$

$T_{p}^{\prime}=\overline{T_{p}} / \overline{T_{g}} \times T_{g}^{\prime}$

Formula (8) gives the AUSM char combustion model that we proposed earlier. $T_{p}^{\prime}$ is the particle temperature fluctuation, $\overline{T_{p}}$ is the mean particle temperature, $\overline{T_{g}}$ is the gas mean temperature, and $T_{g}^{\prime}$ represents the gas temperature fluctuation. There is a simple assumption that the ratio of particle temperature to gas temperature equals the ratio of particle temperature fluctuation to gas temperature fluctuation, so that $T_{p}^{\prime}$ can be expressed by formula (9), which avoids solving the particle temperature conservation equation. Formula (10) gives the classical char combustion model, from which it can be seen that the effect of particle temperature fluctuation on the char chemical reaction rate is totally eliminated:

$$
\begin{aligned}
& \dot{m}_{c, p}^{1}=-\frac{1}{\beta_{c 1}} \pi d_{p}^{2} \rho_{S} Y_{\mathrm{O}_{2}, S} B_{1} \exp \left(-\frac{E_{1}}{R \overline{T_{p}}}\right) \\
& \dot{m}_{c, p}^{2}=-\frac{1}{\beta_{c 2}} \pi d_{p}^{2} \rho_{S} Y_{\mathrm{O}_{2}, S} B_{2} \exp \left(-\frac{E_{2}}{R \overline{T_{p}}}\right) \\
& \dot{m}_{c, p}^{3}=-\frac{1}{\beta_{c 3}} \pi d_{p}^{2} \rho_{S} Y_{\mathrm{CO}_{2}, S} B_{3} \exp \left(-\frac{E_{3}}{R \overline{T_{p}}}\right)
\end{aligned}
$$

There is still an assumption made for both the E-L and E-E calculations; i.e. that the diameter of a coal particle will not be changed during coal combustion. However, the density of the coal particle will decrease due to combustion.

The chemical kinetic mechanisms of the three heterogeneous reactions that are used for both the E-L model and the E-E model in the present study are shown in Table 2 . It should be noted that this mechanism is widely used for the prediction of the $\mathrm{CO}_{2}$ and coal burnout rates; however, in terms of chemistry, it is only a simplified mechanism that cannot make meaningful predictions about detailed flue gas components such as $\mathrm{CO}$. A more complex mechanism must be applied for considering $\mathrm{CO}$ concentration. Given the research objective and the limitation of the mechanism used, this study considers only the $\mathrm{CO}_{2}$ concentration.

\subsection{Other sub-models}

In order to make direct comparisons, the same sub-models were used for both the E-E and the E-L simulations. They are: the $k-\varepsilon$ gas turbulence model, the EBU-Arrhenius volatile and CO combustion model, the six-flux radiation model, the two-step coal devola-

Table 1

Parameters of the basic calculation.

\begin{tabular}{lll}
\hline Parameter & Unit & Value \\
\hline Coal mass flow & $\mathrm{kg} / \mathrm{h}$ & 1.0 \\
Wall temperature & ${ }^{\circ} \mathrm{C}$ & 1250 \\
Volume flow of coal-carrying air & $\mathrm{N} \mathrm{m}^{3} / \mathrm{h}$ & 1.5 \\
Temperature of coal-carrying air & ${ }^{\circ} \mathrm{C}$ & 200 \\
Primary air + secondary air & $\mathrm{N} \mathrm{m}^{3} / \mathrm{h}$ & 8.0 \\
Primary air/secondary air & - & $1: 2$ \\
Temperature of primary air & ${ }^{\circ} \mathrm{C}$ & 250 \\
Temperature of secondary air & ${ }^{\circ} \mathrm{C}$ & 350 \\
Mean particle diameter & $\mu \mathrm{m}$ & $16,52,160,350$ \\
Percentage of particles & $\%$ & $30,35,25,10$ \\
\hline
\end{tabular}

Table 2

Chemical kinetic mechanisms of three heterogeneous reactions.

\begin{tabular}{lll}
\hline & $B(\mathrm{~m} / \mathrm{s})$ & $E(\mathrm{~J} / \mathrm{mol})$ \\
\hline $\mathrm{C}+\mathrm{O}_{2} \rightarrow \mathrm{CO}_{2}$ & $1.225 \times 10^{3}$ & $9.977 \times 10^{4}$ \\
$2 \mathrm{C}+\mathrm{O}_{2} \rightarrow 2 \mathrm{CO}$ & $1.813 \times 10^{3}$ & $1.089 \times 10^{5}$ \\
$\mathrm{C}+\mathrm{CO}_{2} \rightarrow 2 \mathrm{CO}$ & $7.351 \times 10^{3}$ & $1.38 \times 10^{5}$ \\
\hline
\end{tabular}

tilization model and the char combustion model that was introduced above [16].

2.5. Ratio of the statistically heterogeneous reaction rate from the $E-L$ simulation to that predicted by the E-E model

The ratio of the heterogeneous reaction rate from the E-L simulation to that predicted by the E-E model is calculated as:

$R_{1}=\frac{-\frac{1}{\beta} \pi d^{2} \rho Y \sum_{i=1}^{n} \exp \left(\frac{E}{R T_{p_{i}}}\right)}{n}$

$R_{2}=-\frac{1}{\beta} \pi d^{2} \rho Y n \exp \left(\frac{E}{R \overline{T_{p}}}\right)$

$\overline{T_{p}}=\frac{\sum_{i=1}^{n} T_{p_{i}}}{n}$

$R a=\frac{R_{1}}{R_{2}}$

where $R_{1}$ is the statistically heterogeneous reaction rate from the E-L simulation and $R_{2}$ is that used in the E-E model, $n$ is the sample number at a given position, $T_{p_{i}}$ is the temperature of particle $i, \overline{T_{p}}$ is the local averaged particle temperature and $R a$ is the ratio of $R_{1}$ to $R_{2}$.

\section{Experimental}

The trial tests were conducted in an entrained flow combustion reactor (see Fig. 1) [14]. The electrically heated reactor has five regulated heating zones. A gravimetric screw conveyor supplies coal at a constant rate. The pulverized coal is carried by air and enters the burner centre, surrounded by the primary air and the secondary air. The furnace is $2.5 \mathrm{~m}$ long and has an internal diameter of $200 \mathrm{~mm}$. Because of the large ratio of the length to the radius (25), the combustor is essentially one-dimensional. Table 1 gives the main test parameters. During gas component testing, the gas sample was kept at $450 \mathrm{~K}$ before entering the flue gas analyser, so that the vapour mass fraction is taken into account. The concentrations of $\mathrm{O}_{2}, \mathrm{CO}$ and $\mathrm{CO}_{2}$ in the flue gas were measured with standard instrumentation (paramagnetic $\mathrm{O}_{2}$ (error 0.5\%); NDIR CO, $\mathrm{CO}_{2}$ (error $2 \%)$ ).

Coal particle sizes were distributed within the range shown in Table 1. For the E-E model, particles with different diameters represent different phases. For the E-L model, particles with different diameters have to be put into different trajectory groups. In order to save computational time, coal particles were assumed to have a uniform diameter of for both the E-E and the E-L simulations here, which is calculated as:

$d_{r}=\sum_{i=1}^{n} d_{i} \alpha_{i}$

This simplification might induce calculation errors for both models and the particle size distribution should be taken into account in future work. 


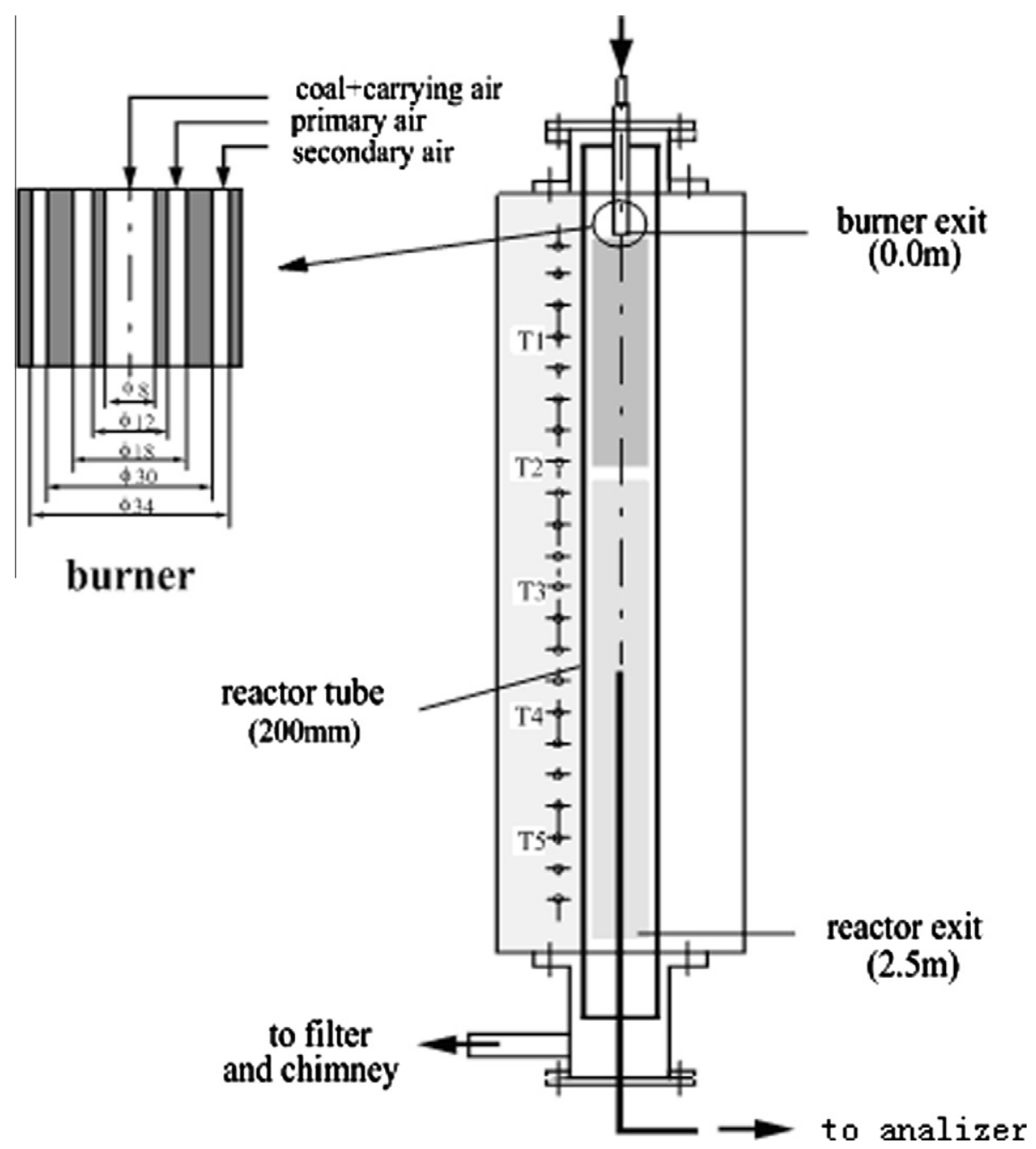

Fig. 1. Schematic of the coal combustor.

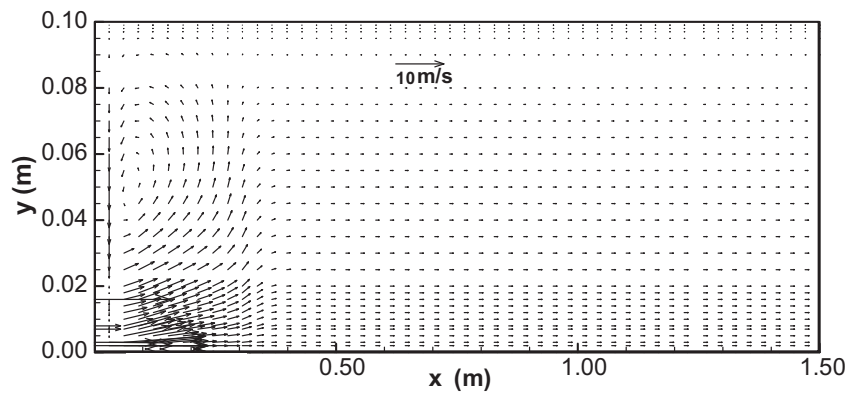

(a) E-E simulation

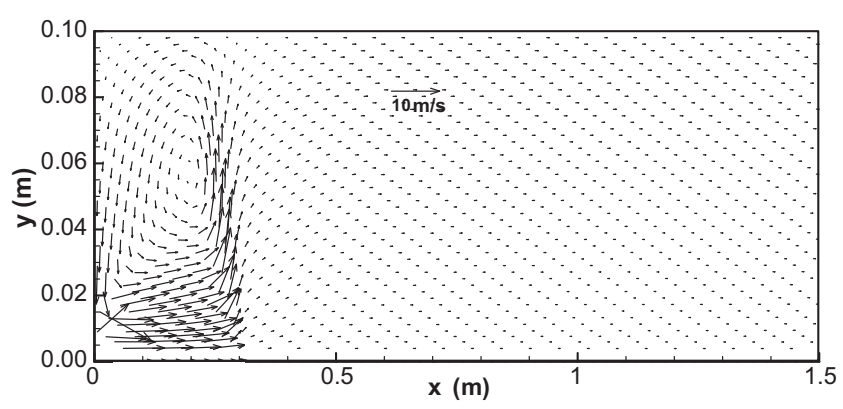

(b) E-L simulation

Fig. 2. Gas velocity field comparison.

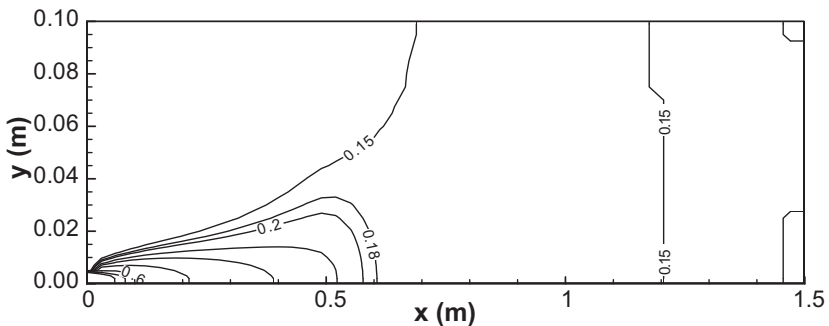

(a) E-E predicted particle volume fraction $\left(10^{-4}\right)$

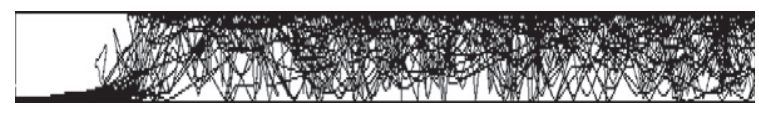

(a) E-L predicted particle tracks

Fig. 3. Particle flow field

\subsection{Simulation conditions}

A 3-D CFD calculation was used for evaluation in both the E-E and the E-L models. The wall temperature, the coal feeding rate, the coal composition, and the flow rates of primary and secondary air were kept constant (Table 1 ) for both E-E and E-L calculations in order to compare the CFD prediction with the experimental data. An outflow boundary condition was used, which indicates that gas velocity in the direction of flow is zero at the outlet. 


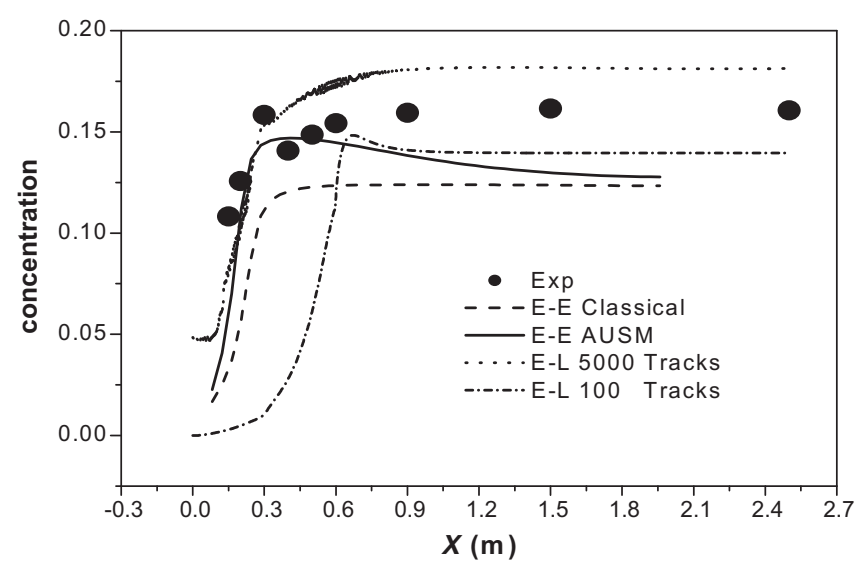

Fig. 4. Carbon dioxide concentration along the reactor length.

\section{Results and discussion}

Fig. 2 shows the overall similarity of the E-E and E-L predicted gas velocities. Both methods successfully predict that there is a reverse flow region at $0.3 \mathrm{~m}$ from the inlet, and this region is $\sim 0.08 \mathrm{~m}$

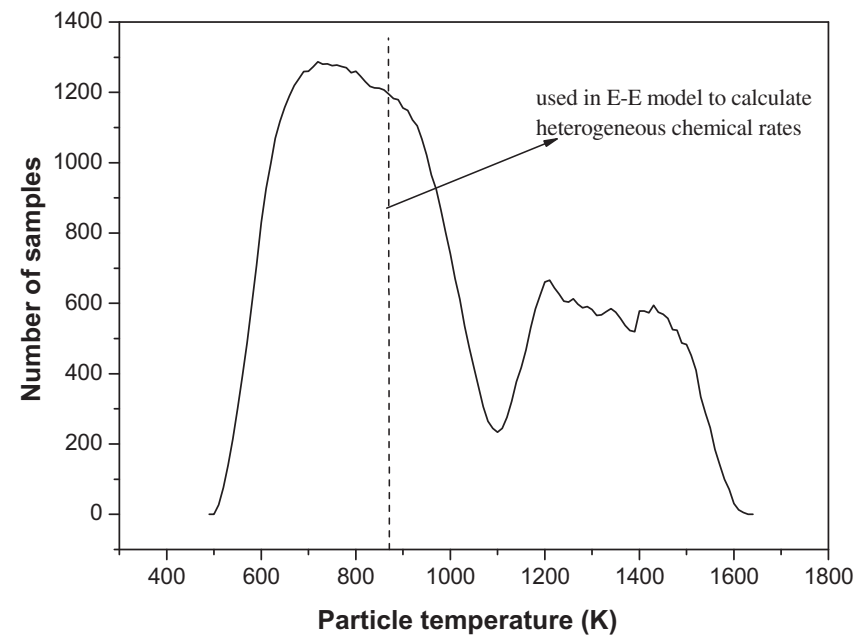

(a) Temperature

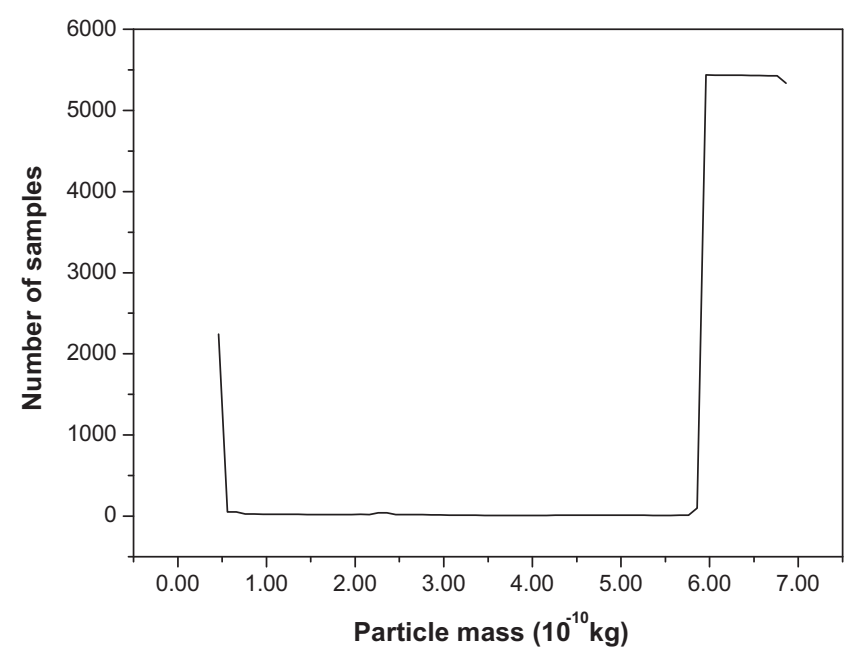

(b) Particle mass

Fig. 5. Particle temperature and mass at $x=0.2 \mathrm{~m}$. in height. Beyond that region, the gas velocity quickly becomes uniform. Fig. 3a shows the E-E predicted particle volume fractions. The particle volume fraction is very small in coal burners; therefore, the collision between particles and the particle volume effect on gas flow can be neglected. This figure shows also that the high particle bulk density exists only at the inlet region; beyond $0.4 \mathrm{~m}$ from the inlet, particles disperse and fill the burner space uniformly. The E-L model, however, cannot give the volume fractions of particles directly. Fig. 3b shows the E-L predicted particle trajectory distribution, and the same trend of particle dispersion can be seen.

Fig. 4 gives the predicted and measured concentrations of $\mathrm{CO}_{2}$, and it is clear that the classical E-E model underestimates the concentration of $\mathrm{CO}_{2}$. The results predicted by the AUSM model are closer to the experimental data but are also underestimates of the concentration of $\mathrm{CO}_{2}$. The results predicted by the $\mathrm{E}-\mathrm{L}$ model that has 5000 particle trajectories are the closest to the experimental data, although it has a tendency to overestimate. It should be noted that the accuracy of the E-L model is very dependent on the number of trajectories; $>5000$ particle trajectories have to be used in this simulation with a small combustor. Fig. 4 shows that when the number of trajectories is reduced to 100 , the values predicted by the E-L model are the worst fit to the experimental data. A low number of representative particles is likely to introduce

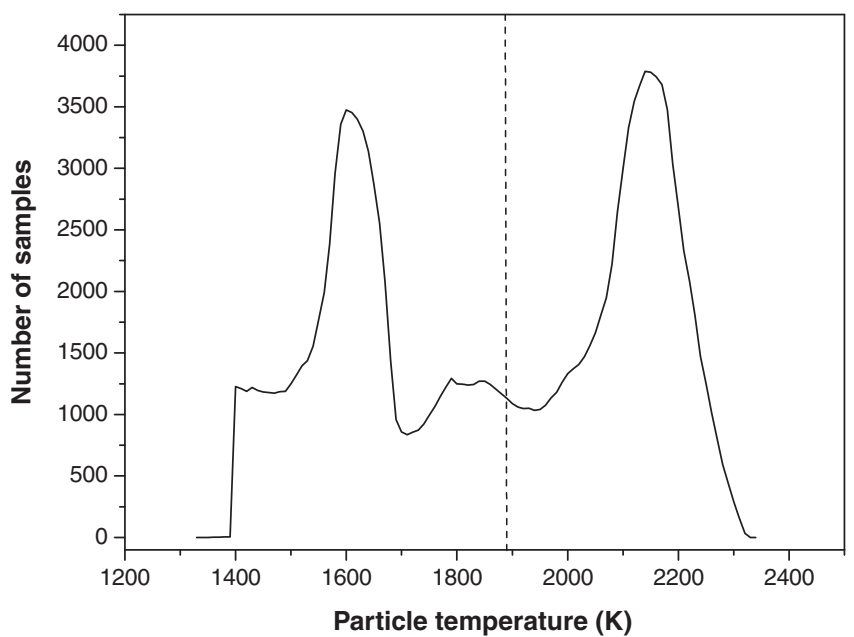

(a) Temperature

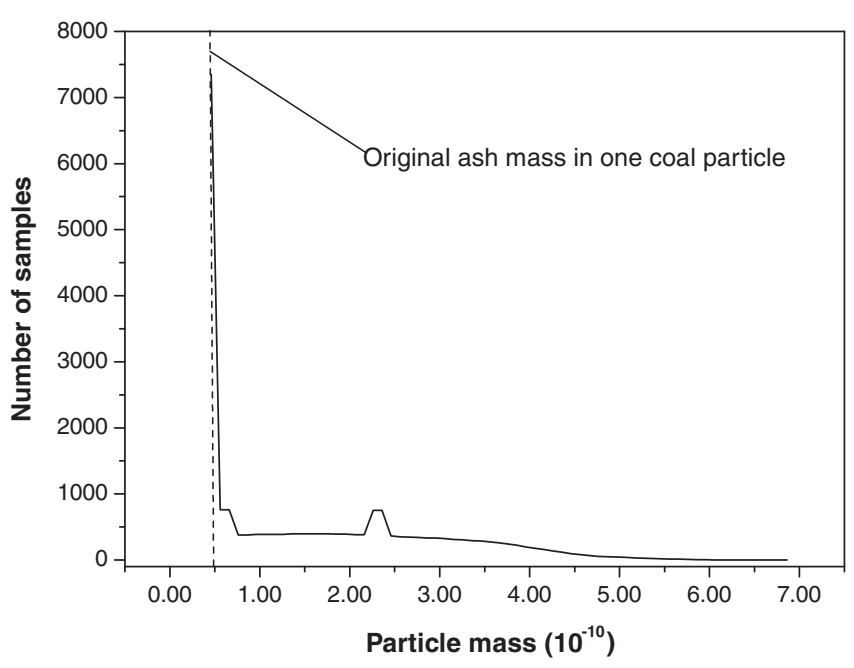

(b) Mass

Fig. 6. Particle temperature and mass at $x=0.4 \mathrm{~m}$. 
random statistical error, which would result in the underestimation of coal combustion [9]. In simulations, the required number of particle trajectories depends strongly on the volume of the simulated object. As a rough guide, the number of trajectories required should have a cubic increase in proportion to the increase of the object volume. However, in a real application, e.g., for the simulation of a utility boiler, in most cases the number of trajectories has to be reduced to make the simulation feasible.

As shown in Fig. 5, some of the particles start to be ignited at $0.2 \mathrm{~m}$ from the inlet and there are two temperature peaks; the lower one is induced by heating and the higher one is induced by volatile combustion. Although the highest temperature of particles is $>1500 \mathrm{~K}$, the local average is still $<900 \mathrm{~K}$. Fig. 5b gives the particle mass at the same position in the combustor. Many particles retain their original mass but some are starting to lose mass by volatile release. Fig. 6a shows that half of the particles remain in volatile combustion whereas the others have been in char combustion at $0.4 \mathrm{~m}$ from the inlet; therefore, there are two peak particle temperatures. Fig. $6 \mathrm{~b}$ shows the particle mass; note, the total mass of some particles is close to the ash mass.

The majority of particles $0.5 \mathrm{~m}$ from the inlet are in char combustion. It can be seen in Fig. 7a that the number of low-temperature peak particles sampled is only half the number of

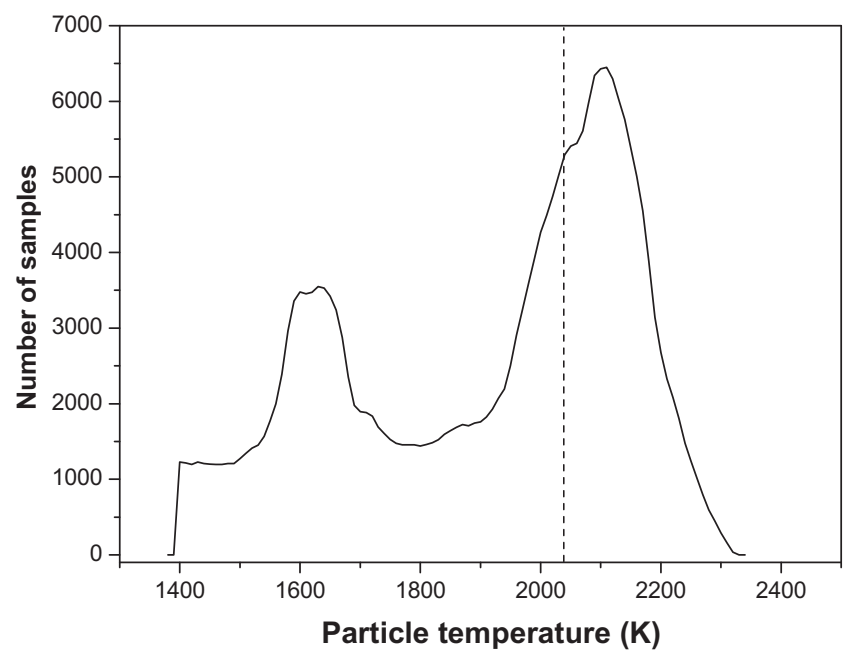

(a) Temperature

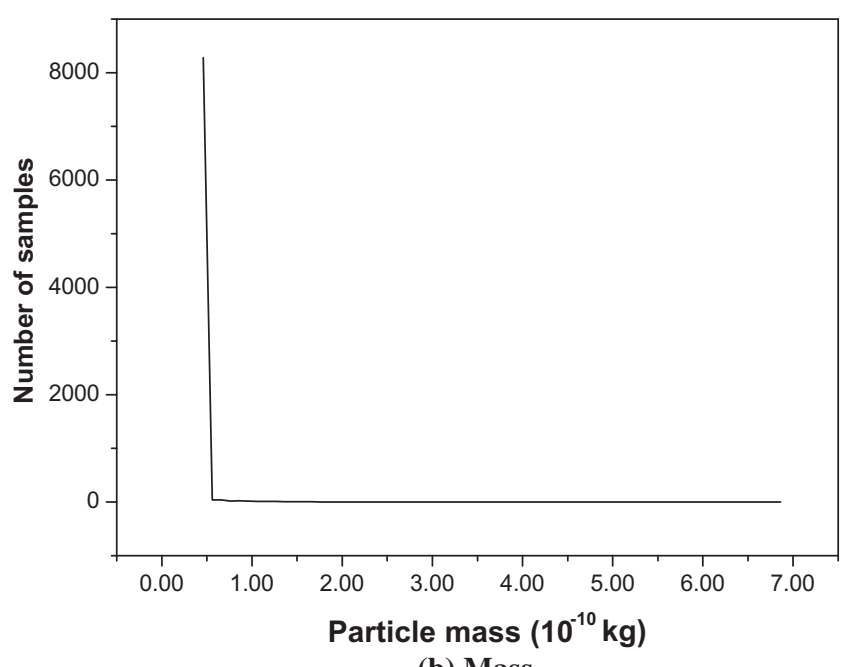

(b) Mass

Fig. 7. Particle temperature and mass at $x=0.5 \mathrm{~m}$. high-temperature peak particles and Fig. 7b shows that almost all particles are burned out at this position.

Fig. 8 illustrates the decrease of particle temperature after combustion. It can be seen that the particle temperature is decreased along the length of the combustor due to heat transfer from particle to gas. Finally, the peak and the local average particle temperatures are the same.

As discussed above, the coal combustion process begins at $0.2 \mathrm{~m}$ and ends at $0.5 \mathrm{~m}$ beyond the inlet of the combustor. Fig. 9 shows the same trend of local average gas and particle temperatures along the combustor. From the inlet to $0.2 \mathrm{~m}$ beyond, the gas temperature is greater than the particle temperature and the gas heats the coal particles. From $0.2 \mathrm{~m}$ to $0.5 \mathrm{~m}$, particle temperatures are greater than the gas temperature due to particle combustion. Here, particles transfer heat back to the gas. After $0.5 \mathrm{~m}$ from the inlet, particle temperature is decreased dramatically because particle combustion has ended and wall cooling starts to control the temperature inside the burner.

Fig. 10 gives the ratio of the heterogeneous reaction rate predicted by the E-L model to that predicted by the E-E model. As the distance increases, the ratio decreases. In general, the E-E model underestimates the reaction rate, especially in the inlet region. At $0.2 \mathrm{~m}$ from the inlet, where coal combustion is beginning, the

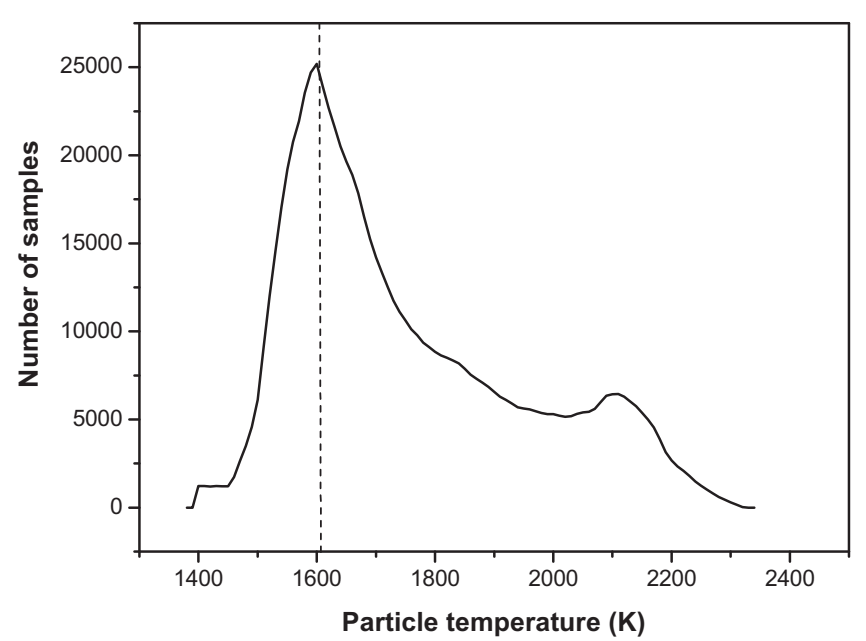

(a) Particle temperatures at $x=1.0 \mathrm{~m}$

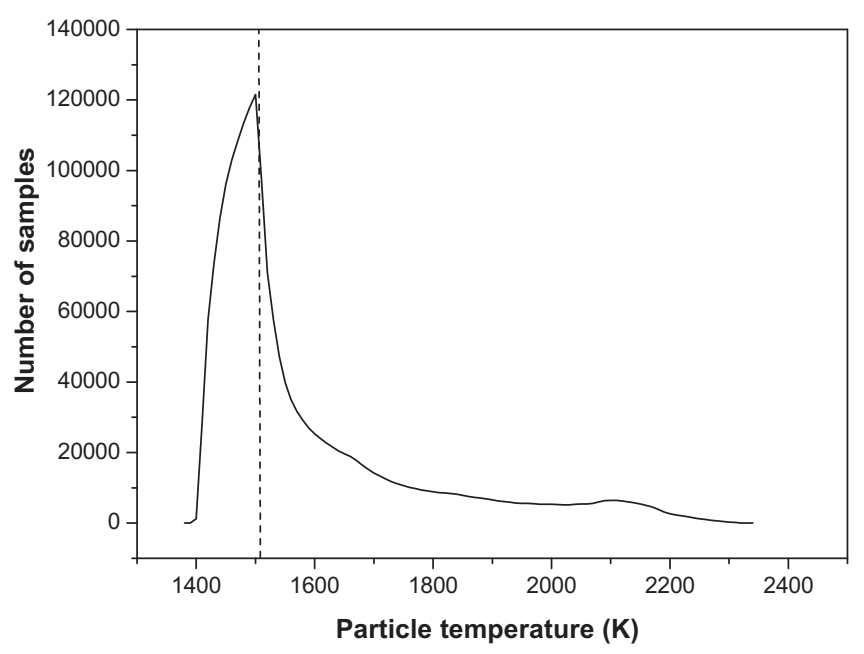

(b) Particle temperatures at $x=2.0 \mathrm{~m}$

Fig. 8. Particle temperatures after char combustion. 


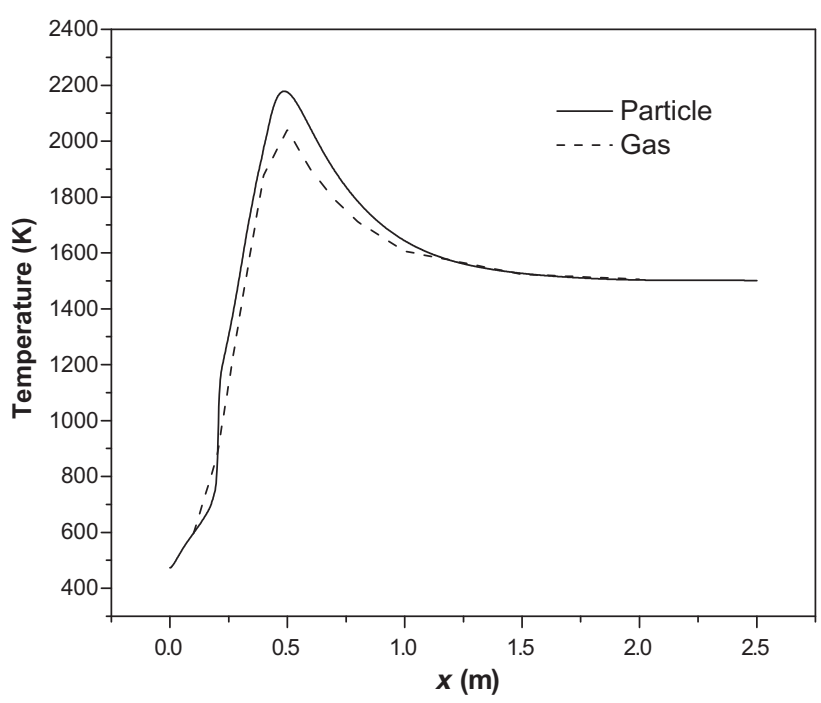

Fig. 9. Particle temperature vs. gas temperature.

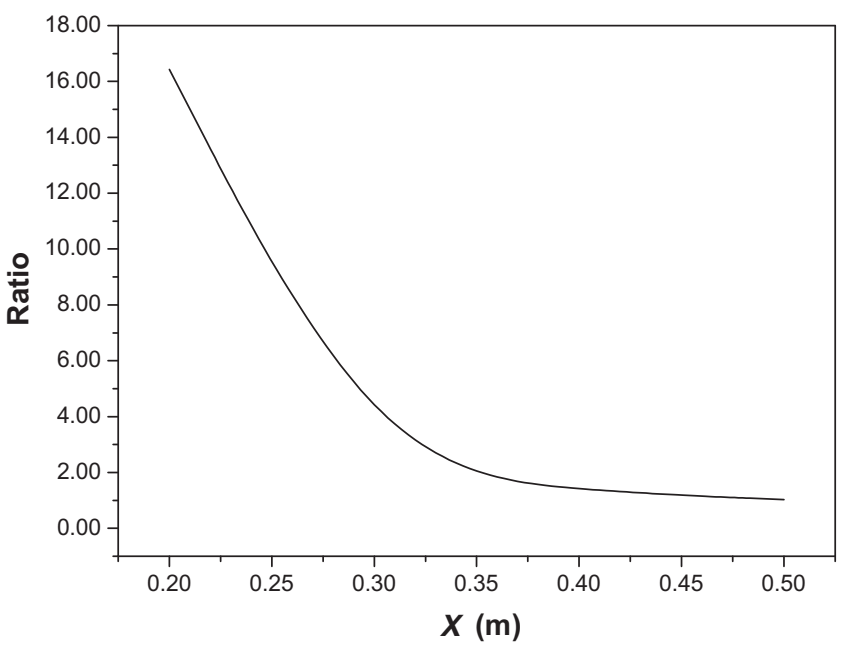

Fig. 10. Ratio of heterogeneous reaction rate obtained by the E-L model to that used in the E-E model.

reaction rate predicted by the E-E model is only $1 / 16$ of that predicted by the E-L model. The comparison explains clearly why the $\mathrm{E}-\mathrm{E}$ model underestimates the concentration of $\mathrm{CO}_{2}$ at the inlet region. Note that the concentration of $\mathrm{CO}_{2}$ predicted by the $\mathrm{E}-\mathrm{E}$ model would not be as low as $1 / 16$ of the E-L prediction because in these calculations the reaction rate of one component determines only the source term and not the final concentration of that component.

It should be noted that the conclusion of this discussion is qualitative. All the quantitative relations of E-E and E-L simulations discussed above are pertinent only to this work.

\section{Summary}

The E-L and E-E models were used to predict the course of coal combustion in a sudden-expanding coal combustor. The results show that the conventional $\mathrm{E}-\mathrm{L}$ model can predict $\mathrm{CO}_{2}$ distribution reasonably when the number of particle trajectories is sufficient. The $\mathrm{E}-\mathrm{E}$ model also gives a reasonable prediction of the trend of the $\mathrm{CO}_{2}$ distribution, but it underestimates the amount of $\mathrm{CO}_{2}$ because fluctuation of particle temperature is not fully accounted for in the calculation of heterogeneous reaction rates. A more accurate heterogeneous reaction sub-model must be developed to improve the performance of the E-E model.

\section{Acknowledgements}

The project is sponsored by the Scientific Research Foundation for the Returned Overseas Chinese Scholars, State Education Ministry and National Natural Science Foundation of China (Project No. 50776099). The authors greatly appreciate the help of the IVD (changed to IFK in 2009), University of Stuttgart during the collection of the test data.

\section{References}

[1] Williams A, Backreedy R, Habib R, Jones JM, Pourkashanian M. Modelling coal combustion: the current position. Fuel 2002;81:605-18.

[2] Zhou LX. Advances in numerical modeling of turbulent reaction of $\mathrm{NO}_{x}$ formation. Adv Mech (China) 2000;30:77-82.

[3] Liao CM, Liu ZN, Zheng XQ Liu CQ. $\mathrm{NO}_{x}$ prediction in 3-D turbulent diffusion flames by using implicit multi-grid methods. Combust Sci Technol 1996;119:219-60.

[4] Zhou LX, Chen XL, Zheng CG, Yin J. Second-order moment turbulencechemistry models for simulating $\mathrm{NO}_{x}$ formation in gas combustion. Fuel 2000;79:1289-301.

[5] Zhou LX, Zhang Y, Zhang J. Simulation of swirling coal combustion using a full two-fluid model and an AUSM turbulence-chemistry model. Fuel 2003;82:1001-7.

[6] Sheng CD, Moghtaderi B, Gupta R, Wall TF. A computational fluid dynamics based study of the combustion characteristics of coal blends in pulverised coalfired furnace. Fuel 2004;83:1543-52.

[7] Song YH, Pohl JH, Beer JM, Sarofim AF. Nitric oxide formation during pulverized-coal combustion. Combust Sci Technol 1982;28:31-9.

[8] Eaton AM, Smoot LD, Hill SC, Eatough CN. Components, formulations, solutions, evaluation, and application of comprehensive combustion models. Prog Energy Combust Sci 1999;25:387-436.

[9] Zhou LX, Li L, Li RX, Zhang J. Simulation of 3-D gas-particle flows and coal combustion in a tangentially fired furnace using a two-fluid-trajectory model. Powder Technol 2002;125:226-33.

[10] Zhang Y, Zhou LX, Wei XL, Sheng HZ. Numerical simulation of $\mathrm{NO}_{x}$ formation in coal combustion with inlet natural gas burning. Chin J Chem Eng 2005;13:318-23.

[11] Chaisemartin SD, Fréret L, Kah D, Laurent F, Foxc RO, Reveillon J, et al. Eulerian models for turbulent spray combustion with polydispersity and droplet crossing. C.R. Mecanique 2009;337:438-48.

[12] Zhang Y, Zhou LX, Wei XL, Sheng HZ. Simulation of coal combustion using an AUSM turbulence-chemistry char combustion model and a full two-fluid model. Fuel 2005;84:1798-804.

[13] Wei XL, Schnell U, Han X, Hein KRG. Interactions of $\mathrm{CO}, \mathrm{HCI}$, and $\mathrm{SO}_{x}$ in pulverised coal flames. Fuel 2004;83:1227-33.

[14] Wei XL, Schnell U, Han X, Hein KRG. Detailed modeling of hybrid reburn/SNCR processes for $\mathrm{NO}_{x}$-reduction in coal-fired furnaces. Combust Flame 2003; $132: 374-86$.

[15] Fluent 6.3 documentation.

[16] Zhou LX, Guo YC, Lin WY. Two-fluid models for simulation reacting gasparticle flows, coal combustion and $\mathrm{NO}_{x}$ formation. Combust Sci Technol 2000;150:161-80. 